\title{
THE REASONS FOR USE AND DESCRIPTION OF THE CIRCUIT WITH LINEAR OPTOCOUPLER IL300
}

\author{
OTAHAL, J[iri] \& HRUSKA, F[rantisek]
}

\begin{abstract}
The paper reveals the reasons for usage circuit with linear optocoupler IL300. It is described interference sources that commonly impact to inputs of embedded systems. Next part of the article discuses possibilities of galvanic separations especial optical separations of signal and requirements to sufficient precision and linearity of these circuits. The third part of article describes in detail behavior of circuit with linear optocoupler IL300.

Key words: electromagnetic compatibility, voltage surges sources inputs protections, linear optocoupler, protection of analog signals
\end{abstract}

\section{INTRODUCTION}

Electromagnetic compatibility (EMC) is the ability of a device, system or device to function properly in an environment in which operate other sources of electromagnetic signals (natural or artificial). At the same time its own electromagnetic activity does not influence its own surroundings impermissibly, neither it does not produce signals which could disrupt other devices (technical or biological)

\begin{tabular}{|c|c|c|}
\hline $\begin{array}{c}\text { Electromagnetic } \\
\text { interference } \\
\text { source }\end{array}$ & $\begin{array}{c}\text { Electromagneti } \\
\text { c interference } \\
\text { coupling way }\end{array}$
\end{tabular}$\longrightarrow \begin{gathered}\text { Electromagnetic } \\
\text { interference } \\
\text { victim }\end{gathered}$

Fig. 1. The electromagnetic interference (EMI) coupling

Figure 1 shows basic coupling from source to electromagnetic interference victim. Electromagnetic interference can be broadcasted throw conductive, capacitive and radiative coupling. EMC issue is very extensive, but it can be divided into two main areas biological systems EMC and technical systems EMC. In the first phase of the coupling sources of electromagnetic interference are described.

It includes both natural sources of interference and artificial sources of interference. Natural sources of electromagnetic interference are electromagnetic processes in the atmosphere, sun, cosmos and other. Artificial sources of electromagnetic interference are resources created by human activity.

The second part deals with the coupling of transmission of electromagnetic interference environment. It describes the way that the energy of interference sources to get to disturbed object.

The third part includes the issue of the disturbed object. The issue deals with the classification of types of disturbing effects on the disturbed object. It is based on the structural and technological analysis of determined electromagnetic resistance.

In reality the interference is not realized between just two objects, but more interference is represented by each object. The procedure for the analysis is processed in a way that the former is taken into account only one source of interference, and disturbed for all other objects. In the next step of analysis is considered an object previously regarded as a source of interference in disturbed object, which removes the other objects that were previously considered to be the receiver noise. When seeking the best EMC system is to consider whether the disruptive effects of interference sources are its functional characteristics or functioning of the device parasitic products. Accordingly, resources are then directed to reduce interference, mainly on the source of interference, disturbed object or transmission coupling between these objects.

\section{INDUSTRIAL INTERFERENCE SOURCES}

The industrial sources of interference are the most important harmonic frequency power supply, which often generate longer alone generators to produce electricity. Higher harmonics will arise in the non-linear impedances in the electrical network. Large industrial sources of interference are high power semiconductor converters and outside the industry in households appliances are sources that have a power rectifier.

Energy networks contain switching and break elements that generate a series of transient phenomena. In the high voltage networks and very high voltage networks switching occurs when the influence of trunk line capacity and inductance of the oscillation frequency in the order of a few $\mathrm{MHz}$. The oscillation duration is usually five to ten times its period and is spread easily through the capacitive coupling to the low voltage networks.

In the activities of mechanical relays, contactors, circuit breakers and low voltage power networks, it rise another type of noise when releasing the contacts under load. Once these elements distancing contact occurs a sharp decrease the current in circuit, and if the impedance of the circuit contains a significant inductive component arises influence interference of high voltage, which is practically across the contacts.

$$
\mathrm{u}=-\mathrm{L} \cdot \frac{\mathrm{di}}{\mathrm{dt}}
$$

Between contacts starts up arc discharge and the voltage falls instantaneously to zero, the discharge goes out again and starts to increase tensions between the contacts. If this voltage exceeds the environment breakdown voltage, the arc lights again. This process can be several times depending on the size of inductive components disconecting circuit again. Between contacts generated pulses with steep saw impulses with very fast rising voltage and frequency in the order of several $\mathrm{kV}$ and frequency of several kHz. Similar interference occurs even when switching circuits with significant inductive impedance components . Within initial conditions is created the smaller pulse size.

Another interference type arises in high power thyristor systems management. In these devices are periodically switched high currents which can greatly distort the supply voltage course. Frequency spectrum of this type of interference 
extends to several tens of $\mathrm{MHz}$. When these devices directly connected into the power network without the filter, they can cause power outages energy networks.

In many applications it is necessary protect devices or components, separate differences in ground potential and safety parts electrically circuit. The galvanic isolation can be use in several ways. The AC power circuits and in circuits of AC voltage measurements can be used to separate transformer. For DC voltage and current transformer for obvious reasons can not be used, however, may use sensors using Hall effect. The optical separation is the most often applied to isolate DC signals.

\section{OPTICAL SEPARATION OF SIGNAL}

Optical Separation of the signal is applied wherever low power signals separation is needed. Optical isolation is often also reach noise restrictions, which can be introduced into the circuit from the external environment such as long route in industrial distribution. The optocoupler is also a demand for components on the input side of the possibility of a major overload of the reasons the greatest resistance to voltage surges.

For galvanic separation this case is used optocouplers. Optocoupler consists of LEDs on one side and a photodiode, phototransistor, or triac photocathode on the other side. The alternative are called icoupler optocouplers that operate on the principle of electromagnetic induction.

-Optocoupler can be separated on analog and digital signals.

-In terms of nature of the signal to be electrically separated, optocouplers can be divided into three groups:

- Optocouplers for digital signals galvanic separation

- Optocouplers for analog signals galvanic separation

-Special optocouplers

\section{LINEAR OPTOCOUPLER}

Optocouplers for analog signals galvanic isolation are formed on either side of the one LED and the other one photodiode. These optocouplers, however, are inherently less linear and for galvanic isolation of analog signals not very appropriate. Linearization is achieved by adding to the other LED photodiode, which is used to compensate optocoupler non-linearity. It should be noted that in order to signal the level of of such subsequently convert 12-bit converter with sufficient precision, linearity optocoupler transfer can have a maximum error of $0.01 \%$. Providing that the photodiode on the other side of the photodiode and on the side of the photodiode has the same properties, nonlinearity is compensated through connecting external components with good stability. This connection also compensates for thermal semiconductor-based components instability. Thermal instability of this involvement varies is typically around $\pm 0.005 \% /{ }^{\circ} \mathrm{C}$. This value is very important when deploying this type of components in real applications.

The picture below is typical performance optocoupler for electrical isolation of analog signals.

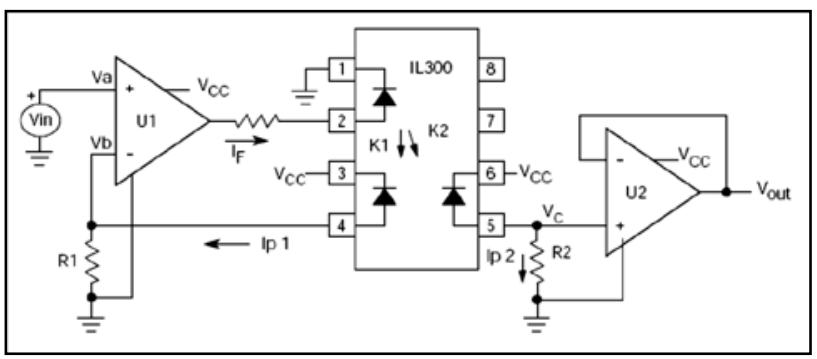

Fig. 2. The linear optocoupler typical connection
The figure above shows a typical linear optocoupler connection. To achieve linearity optocoupler is needed to compensate for photodiodes nonlinearity and the photodiodes threshold voltage. Typical connection uses for the input the operational amplifier. Through photodiode and feedback resistor $R_{1}$ flows the current $I_{P 1}$. This current is on resistor $R_{1}$ which is connected to the inverting input of operational amplifier $\mathrm{U}_{1}$

$$
I_{P 1}=\frac{V_{I N}}{R_{1}}
$$

As is evident from the picture above, the photodiode on the LED side is connected to the inverting operational amplifier input . Input voltage is given by

$$
\frac{V_{I N}}{R_{1}}=K_{1} \cdot I_{F}
$$

The photodiode output on the other side is connected to the noninverting input of the output operational amplifier. When current flows through the photodiode, this current flows through resistor $R_{2}$. The current in resistor $R_{2}$ as is evident creates voltage. The output of the op amp output is:

$$
V_{0}=I_{F} \cdot K_{2} \cdot R_{2}
$$

Therefore, the total transfer function $\left(\mathrm{V}_{\mathrm{o}} / \mathrm{V}_{\text {in }}\right)$ is the result of the ratio of the output operational amplifier $\mathrm{U}_{2}$ and the load resistance R2 and photodiode feedback circuit with a resistor $\mathrm{R}_{1}$. This circuit reduces the nonlinearity of LEDs and photodiodes to:

$$
\frac{V_{0}}{V_{I N}}=\frac{K_{2} \cdot R_{2}}{K_{1} \cdot R_{1}}
$$

The final transfer function is completely independent of the current through the LED. The entire circuit gain is given as the resistors $\mathrm{R} 1$ and $\mathrm{R} 2$ ratio:

$$
\frac{V_{0}}{V_{I N}}=K_{3} \cdot \frac{R_{2}}{R_{1}} ; K_{3}=\frac{K_{2}}{K_{1}}
$$

\section{CONCLUSION}

The goals of this article are describe in detail behavior of circuit with linear optocoupler IL300 and reasons of usage linear optocouplers. Another part of the work is a mathematical description of the behavior of circuit with linear optocoupler IL300 and model this circuit behavior in Matlab Simulink .

\section{ACKNOWLEDGEMENTS}

This paper is supported by the Internal Grant Agency at Tomas Bata University in Zlin, project No. IGA/32/FAI/11/D and by the EuropeanRegional Development Fund under the project CEBIA-Tech No.CZ.1.05/2.1.00/03.0089.

\section{REFERENCES}

Svačina, J. (2000). Zdroje rušivých signálů a vazební mechanismy jejich přenosu [online], Available from: WWW:<http://www.elektrorevue.cz/clanky/00031/index.ht ml\#kapI>.Accessed:2009-20-04

STMicroelectronics. (1998). Datasheet

IL300 